\title{
The Effect of Vitamin D3, Vitamin B6, Selenium and Some Electrolytes on the Women with Nausea and Vomiting of Pregnancy in Thi-Qar Government -Iraq
}

\author{
Nadia A. Jomah ${ }^{1}$, Husam M. Kredy ${ }^{2}$, Nadia S. Al Assady ${ }^{3}$ \\ ${ }^{1}$ Post Graduate, ${ }^{2}$ Prof., College of Sciences, University of Thi-Qar/Iraq, \\ ${ }^{3}$ Asst. Prof., College of Medicine, University of Thi-Qar/Iraq
}

\begin{abstract}
Objective: Nausea and vomiting (NVP) are among the most common symptoms during pregnancy. NVP causes emotional and psychological distress and can have a profound impact on a woman's quality of life (QoL).

Material and Method: Vitamin D3 and Vitamin B6,se and electrolytes $\left(\mathrm{Mg}^{+2}, \mathrm{~K}^{+}\right)$levels were determined in first and second trimesters in 120 women suffering from nausea and vomiting of pregnancy,30 pregnant women free of symptoms, age identical between the ages of (17-45) years.

Results: Vitamin D3 Vitamin $\mathrm{B} 6, \mathrm{~K}^{+}, \mathrm{Se}$ and $\mathrm{Mg}^{+2}$ in the blood showed a significant decrease in all patients as compared to control group $(\mathrm{P} \leq 0.05)$.

Conclusion: In patients with NVP and NP we find a significant reduction in level of Vit.D3, and decrease in level of serum Vit. B6, $\mathrm{K}^{+}$, Se and $\mathrm{Mg}^{+2}$. In first trimester found a decrease in levels of Vit.D3, Vit.B6 and $\mathrm{K}^{+}$ more from second trimester,while in first trimester found an increase in levels $\mathrm{Se}, \mathrm{Mg}^{+2}$ more from second trimester.
\end{abstract}

Keywords: Pregnancy, Nausea and vomiting (NVP), First and Second trimesters, Vitamin D3, Vitamin B6, Selenium, Potassium, Magnesium.

\section{Introduction}

Nausea and vomiting are among the most common symptoms during pregnancy, affecting $50-90 \%$ of all pregnant women ${ }^{(1)}$.This condition usually begins at weeks 4-8 after menstruation and is more severe in the 9th week. It starts to decrease in the following weeks and most cases, improves until the 14th week; however, it continues during the whole pregnancy in $2 \%$ of the cases $^{(2)}$. The most severe form of NVP, Hyperemesis gravidarum $(\mathrm{HG})$, is characterized by severe and

\section{Corresponding Author:}

\section{Husam M. Kredy}

Prof., College of Sciences, University of Thi-Qar/Iraq

e-mail: hmk20001999@gmail.com persistent nausea and vomiting leading to weight loss, ketonuria, nutritional deficiencies, dehydration, and electrolyte imbalance, often so severe as merits hospitalization $^{(3)}$. Vitamins and minerals are collectively referred to as micronutrients and have an important influence on the health of pregnant women and growing fetus $^{(4)}$ Vitamin D is a fat-soluble vitamin. It is also synthesized within skin cells on sunlight $\operatorname{contac}^{(5)}$. Vitamin D is a well-known immunomodulatory and anti inflammatory agent in the body ${ }^{(6)}$. Low serum 25-hydroxyvitamin D3 [25(OH)D] levels have been related to adverse obstetric outcomes such as preterm birth, low birth weight, hypertension, and gestational diabetes mellitus (GDM) ${ }^{(7)}$. Vitamin B6,a water soluble vitamin. VitaminB6 functions as a coenzyme in many reactions that are involved in amino acid, carbohydrates, and lipid metabolism ${ }^{(8)}$. Vitamin B6 deficiency has 
been proposed as a cause for NVP too ${ }^{(9)}$. Vitamin B6 supplementation may be important for achieving adequate intake during pregnancy ${ }^{(10)}$. Selenium plays an important role in the maintenance of human health ${ }^{(12)}$. It a vital intracellular antioxidant that prevents oxidative cellular damage ${ }^{(12)}$. The demand for selenium during pregnancy is increased to support optimal fetal growth, resulting in decreased maternal blood and tissue concentrations of selenium ${ }^{(13)}$. Electrolytes are present in the human body, and the balance of the electrolytes in bodies is essential for the normal function of the cells and organs ${ }^{(14)}$. Magnesium $\left(\mathrm{Mg}^{+2}\right)$ is the fourth most abundant cation in the body and the second most abundant intracellular ion ${ }^{(15)}$. Pregnancy represents a physiological situation with increased magnesium requirement ${ }^{(16)}$. An adequate magnesium intake also seems to be important for further healthy development in pregnancy ${ }^{(17)}$. Potassium $\left(\mathrm{K}^{+}\right)$is a very important mineral to the human body for Building proteins, Break down and use carbohydrates, Building muscle, maintain normal body growth, control the electrical activity of the heart and control the acid-base balance ${ }^{(15)}$.

\section{Material and Method}

This study conducted at the Bent Al-Huda hospital in Thi-Qar Governorate/Iraq, biochemistry laboratory, the hormones and immunology laboratory, the specialized clinics. It included (150) subjects, the control group consisting of (30) women Symptom -free (SF) and patients (120).A bout (5mL) of blood samples of NVP patients and controls. Analyzed Vitamin D3,Vitamin B6, electrolet and Se. Vitamn D3 in serum was analyzed by ELISA instrument, kits supplied by Calbiotech,USA . Serum vitamin B6 was analyzed by (ELISA) instrument, kits supplied by Elabscience, USA. Serum $\mathrm{Mg}^{+2}$ and $\mathrm{K}^{+}$was analyzed by enzymatic colorimetric method by
UV/VIS spectrophotometer, kits supplied by (S.A.E), Egypt. Concentrations of selenium element in serum samples were measured by flame atomic absorption device, at the college of sciences/university of ThiQar. Excluded cases: non-pregnant women, smokers, pregnant women with diabetes, preeclampsia, heart disease, patients with chronic diseases. Statistical Analysis: All statistical analysis was performed using SPSS, Windows version 24.0 software and Microsoft Excel 2010. the results were expressed as mean \pm standard deviations (mean \pm SD), and Least Significant Difference (LSD).One way analysis of variance (ANOVA) was used to compare parameters in different studied groups. $\mathrm{P}$-values $(\mathrm{P} \leq 0.05)$ were considered statistically significant.

\section{Results}

In this study, we identified the effect of NVP and $\mathrm{NV}$ on pregnancy womans in first and second trimesters in Vitamins (D3 and B6), Electrolytes $\left(\mathrm{Mg}^{+2}\right.$ and $\left.\mathrm{K}^{+}\right)$and trace elements (Se). The levels of biochemical markers in pregnancy (Vit.D3, Vit $\mathrm{B} 6, \mathrm{Se}, \mathrm{Mg}^{+2}, \mathrm{~K}^{+}$) showed a significant decrease in NVP and NP patients compared to the control group. We also identified the effect of pregnancy period (first trimester) (1st),(second trimester) (2nd) on those parameters biochemical, and the results indicate a significant decrease in the concentration of vitamin D3 (Vit.D3) in (1st) compared to (2nd)compared to the control groups.As shown a significant decrease in the concentration of(Vit.B6 and $\mathrm{K}^{+}$) in (1st) compared to $(2 \mathrm{nd})$. The results showed a significant increase in the levels of $\left(\mathrm{Se}\right.$ and $\left.\mathrm{Mg}^{+2}\right)$ in (1st) compared to (2nd), We also identified the correlation between (V.D3) and with those parameters biochemical and the results showed positive correlation.

Table (1): Serum vitamin D3 and vitamin B6 Test for patients with NVP,NP and the controls.

\begin{tabular}{|c|c|c|c|c|}
\hline \multicolumn{2}{|c|}{ Groups } & \multirow{2}{*}{$\begin{array}{c}\text { No. } \\
30\end{array}$} & \multirow{2}{*}{$\begin{array}{c}\text { Vit.D3 (ng/ml) Mean } \pm \text { SD } \\
2.02 \pm 0.15^{\mathrm{e}}\end{array}$} & \multirow{2}{*}{$\begin{array}{c}\text { Vit.B6 (ng/ml) Mean } \pm \text { SD } \\
30.38 \pm 2.04^{\mathrm{c}}\end{array}$} \\
\hline NVP & $1 \mathrm{st}$ & & & \\
\hline NVP & 2nd & 30 & $2.52 \pm 0.21^{\mathrm{d}}$ & $34.11 \pm 2.01^{\mathrm{b}}$ \\
\hline NP & $1 \mathrm{st}$ & 30 & $3.20 \pm 0.43^{\mathrm{c}}$ & $34.33 \pm 1.59^{\mathrm{b}}$ \\
\hline NP & 2 nd & 30 & $3.60 \pm 0.30^{\mathrm{b}}$ & $34.9 \pm 1.34^{\mathrm{b}}$ \\
\hline Control & \multicolumn{2}{|c|}{30} & $8.52 \pm 1.12^{\mathrm{a}}$ & $50.27 \pm 2.17^{\mathrm{a}}$ \\
\hline Lsd & \multicolumn{3}{|c|}{0.14} & 0.80 \\
\hline
\end{tabular}


Table (2): Serum Se, $\mathrm{Mg}^{+2}$ and $\mathrm{K}^{+}$Tests for patients with NVP,NP and the controls.

\begin{tabular}{|c|c|c|c|c|c|}
\hline \multicolumn{2}{|c|}{ Group } & No & Se (mg/l) Mean \pm SD & $\mathbf{M g}^{+\mathbf{2}}(\mathbf{m g} / \mathbf{d l}) \mathbf{M e a n} \pm \mathbf{S D}$ & $\mathbf{K}^{+\mathbf{1}}(\mathbf{m m o l} / \mathbf{L})(\mathbf{M e a n} \pm \mathbf{S D})$ \\
\hline NVP & 1 st & 30 & $7.13 \pm 0.43^{\mathrm{b}}$ & $2.22 \pm 0.11^{\mathrm{b}}$ & $3.44 \pm 0.81^{\mathrm{c}}$ \\
\hline NVP & 2nd & 30 & $3.86 \pm 0.37^{\mathrm{e}}$ & $2.11 \pm 0.61^{\mathrm{b}}$ & $4.08 \pm 0.57^{\mathrm{b}}$ \\
\hline NP & 1 st & 30 & $6.68 \pm 0.63^{\mathrm{c}}$ & $2.24 \pm 0.04^{\mathrm{b}}$ & $4.24 \pm 0.62^{\mathrm{b}}$ \\
\hline NP & 2nd & 30 & $5.37 \pm 0.54^{\mathrm{d}}$ & $2.13 \pm 0.46^{\mathrm{b}}$ & $4.26 \pm 0.49^{\mathrm{b}}$ \\
\hline Control & & 30 & $7.60 \pm 0.52^{\mathrm{a}}$ & $2.40 \pm 0.12^{\mathrm{a}}$ & $5.25 \pm 1.02^{\mathrm{a}}$ \\
\hline Lsd & & & 0.22 & 0.15 & 0.31 \\
\hline
\end{tabular}

* Each value represents mean \pm SD values with non-identical superscript (a, b, or c...etc.), which were considered significant differences $(\mathrm{P} \leq 0.05)$.

-No: Number of subjects., NVP: Nausea and vomiting in pregnancy, NP: Nausea in pregnancy, SD: Standard deviation.,LSD: Least Significant Difference.

\section{Discussion}

Our study is the first to include a clinical study of vitamins and elements and their effect and classification of nausea and vomiting during pregnancy during the first and second trimesters of pregnant women with NP and NVP and asymptomatic pregnant women. Morning sickness is a frequent symptom in pregnancy, the pregnant woman has nausea or vomiting at various levels due to gestational hormone increase (HCG), leading to dehydration, weight loss, malnutrition, and micro-nutrient deficiency as well. Vitamin D is a wellknown immunomodulatory and anti-inflammatory agent in the body ${ }^{(18)}$. Pregnant women with morning sickness had a double increase in vitamin D deficiency risk versus pregnant women without morning sickness at $\mathrm{P}<0.05^{(19)}$. Table (1), show a significant decrease in the concentration of serum Vit.D3 in all patient with NVP,NP in comparison with control groups, There was no significant difference in the prevalence of $25(\mathrm{OH})$ D deficiency $(25(\mathrm{OH}) \mathrm{D}, 50 \mathrm{nmol} / \mathrm{l})$ among pregnant women in the three different trimesters ${ }^{(20)}$ nutrients from vitamins and supplements in addition to foods, however, revealed that the intake of many micronutrients increased substantially from the 1 st to 2 nd trimester ${ }^{(21)}$. Vitamin D deficiency is a widespread global problem, which even can observe in the countries which get enough sunlight ${ }^{(21)}$. Considering the factors affecting vitamin D production such as clothing type, skin color, and the time of day being exposed to the sun ${ }^{(22)}$. Table (1), show a significant decrease in the concentration of serum Vit.B6 in all patient with NVP, NP in comparison with control groups. Vitamin B6 deficiency is associated with more severe NVP symptoms ${ }^{(23)}$.During pregnancy, pyridoxine contributes to the embryonic development of the central nervous system influencing brain development and cognitive function; therefore, maternal vitamin B6 deficiency may have negative long-term neuro developmental consequences on the fetus ${ }^{(24)}$. The first-line treatment for nausea and vomiting is vitamin B6 which has been evaluated in many controlled trials fo the treatment of morning sickness. it is found a vitamin that B6 reduces nausea and vomiting in early pregnancy ${ }^{(25)}$. However, safety and efficacy studies have determined doses up to $200 \mathrm{mg}$ per day may be useful in managing $N_{V P}{ }^{(23)}$. Table (2), show a significant decrease in the concentration of serum $\mathrm{Se}$ in all patient with NVP,NP in comparison with control groups. In a previous study, the antioxidant activity was significantly lower in Women with NVP compared to healthy pregnant women. Some theories may explain the decreased levels of antioxidants in NVP in the study. The decreased dietary intake of most nutrients rich in antioxidants is observed in women with $\mathrm{NVP}^{(26)}$. Selenium is believed to be one of the most important antioxidant nutrients in the human body, and selenoproteins have a protective effect against oxidative stress and inflammation ${ }^{(27)}$.Various studies have demonstrated that during pregnancy, the whole blood and plasma selenium concentrations, and the activity of glutathione peroxidase in red cells and plasma decline in a linear fashion from the first trimester to parturition ${ }^{(28)}$. The demand for selenium during pregnancy is increased to support optimal fetal growth, resulting in decreased maternal blood and tissue concentrations of selenium ${ }^{(13)}$. Table (2), show a significant decrease in the concentration of serum $\mathrm{Mg}^{+2}$ in all patient with NVP,NP in comparison with control groups. In a previous study serum $\mathrm{Mg}^{2+}$ concentration during pregnancy was significantly lowered to a value 
considered to be deficiency starting appears at the first trimester and continues to decline during the rest of pregnancy have a significant negative correlation with pregnancy duration ${ }^{(29)}$. The reduction of serum $\mathrm{Mg}^{2+}$ level during pregnancy is mainly attributed to fetal growth demand or because of nutritional status during pregnancy. Many explanations behind this reduction, it is most likely due to the fetus and placenta absorb huge amounts of nutrients particularly magnesium from the mother ${ }^{(30)}$. Early signs of deficiency can include loss of appetite, nausea, vomiting, fatigue, and weakness ${ }^{(31)}$. Table (2), show a significant decrease in the concentration of serum $\mathrm{K}^{+}$in all patient with NVP,NP in comparison with control groups. The concentration of $\left(\mathrm{K}^{+}\right)$in the serum is a balance among intake, excretion, and distribution between the extra-and intracellular spaces $^{(32)}$. A patient with Hyperemesis gravidarum (HG) frequently vomits gastric juice and, thus, the loss of hydrogen ions, sodium, chloride, and water in gastric contents leads to chloride-sensitive metabolic alkalosis, dehydration, and extracellular fluid (ECF) volume reduction ${ }^{(33)}$ causing elevated activity of the renin-angiotensin-aldosterone system (RAAS) ${ }^{(33)}$. This activated RAAS, in turn, increases the urinary excretion of potassium, compounding the hypokalaemia ${ }^{(34)}$.

\section{Conclusion}

Vitamin D is has a key role in the etiopathogenesis of nausea and vomiting pregnancy because vitamin D deficiency might lead to problems in immune regulation.

Ethical Clearance: The Research Ethical Committee at scientific research by ethical approval of both MOH and MOHSER in Iraq.

Conflict of Interest: None

Funding: Self-funding

\section{Reference}

1. McParlin, C., O'Donnell, A., Robson, S. C., Beyer, F., Moloney, E., Bryant, A., ... \& Norman, J. Treatments for hyperemesis gravidarum and nausea and vomiting in pregnancy: a systematic review. Jama, 2016; 316(13), 1392-1401.

2. Firouzbakht, M., Nikpour, M., Jamali, B., \& Omidvar, S. Comparison of ginger with vitamin B6 in relieving nausea and vomiting during pregnancy. Ayu, 2014; 35(3), 289.

3. Einarson, T. R., Piwko, C., \& Koren, G. Prevalence of nausea and vomiting of pregnancy in the USA: a meta-analysis. Journal of Population Therapeutics and Clinical Pharmacology, 2013; 20(2).

4. Rathore, S., Gupta, A., Batra, H. S., \& Rathore, R. Comparative study of trace elements and serum ceruloplasmin level in normal and pre-eclamptic pregnancies with their cord blood, 2011.

5. Norman, A. W. A vitamin D nutritional cornucopia: new insights concerning the serum 25-hydroxyvitamin D status of the US population, 2008, 1455-1456.

6. Ota, K., Dambaeva, S., Han, A. R., Beaman, K., Gilman-Sachs, A., \& Kwak-Kim, J. Vitamin $\mathrm{D}$ deficiency may be a risk factor for recurrent pregnancy losses by increasing cellular immunity and autoimmunity. Human reproduction, 2014; 29(2), 208-219.

7. Park, S., Yoon, H. K., Ryu, H. M., Han, Y. J., Lee, S. W., Park, B. K., ... \& Kim, S. H. Maternal vitamin $\mathrm{D}$ deficiency in early pregnancy is not associated with gestational diabetes mellitus development or pregnancy outcomes in Korean pregnant women in a prospective study. Journal of nutritional science and vitaminology, 2014; 60(4), 269-275.

8. Eliot, A. C., \& Kirsch, J. F. Pyridoxal phosphate enzymes: mechanistic, structural, and evolutionary considerations. Annual review of biochemistry, 2004; 73(1), 383-415.

9. Niebyl, J. R. Nausea and vomiting in pregnancy. New England Journal of Medicine, 2010; 363(16), 1544-1550.

10. Masih, S. P., Plumptre, L., Ly, A., Berger, H., Lausman, A. Y., Croxford, R., ... \& O'Connor, D. L. Pregnant Canadian women achieve recommended intakes of one-carbon nutrients through prenatal supplementation but the supplement composition, including choline, requires reconsideration. The Journal of nutrition, 2015; 145(8), 1824-1834.

11. Smith, J. A. R. S., Refuerzo, J., \& Ramin, S. Treatment and outcome of nausea and vomiting of pregnancy. UpToDate. Waltham, MA (accessed 8 Jun 2013),2014.

12. Di Bella, S., Grilli, E., Cataldo, M. A., \& Petrosillo, N. Selenium deficiency and HIV infection. Infectious Disease Reports, 2010; 2(2).

13. Kupka, R., Msamanga, G. I., Spiegelman, D., Morris, S., Mugusi, F., Hunter, D. J., \& Fawzi, W. W. Selenium status is associated with accelerated 
HIV disease progression among HIV-1-infected pregnant women in Tanzania. The Journal of nutrition, 2004; 134(10), 2556-2560.

14. Coso, J. D., Estevez, E., Baquero, R. A., \& MoraRodriguez, R. Anaerobic performance when rehydrating with water or commercially available sports drinks during prolonged exercise in the heat. Applied Physiology, Nutrition, and Metabolism, 2008; 33(2), 290-298.

15. Ahmed, N. B. A. Assessment of the Associations between Serum Electrolytes (Sodium, Potassium, Calcium and Magnesium) and Sudanese Hypertensive patients in Different Hospitals at Khartoum State-Sudan (Doctoral dissertation, Rashid Eltayeb Abdalla), 2018.

16. Young, G., \& Jewell, D. Interventions for leg cramps in pregnancy. Cochrane database of systematic reviews, 2015; 11;(8):CD010655.

17. Yang, S. J., Hwang, S. Y., Baik, S. H., Lee, K. W., Nam, M. S., Park, Y. S.; \& Yim, C. H. Serum magnesium level is associated with type 2 diabetes in women with a history of gestational diabetes mellitus: the Korea National Diabetes Program study. Journal of Korean Medical Science, 2014; 29(1), 84-89.

18. Yılmaz, S., Cırık, D. A., Demirtaş, C., Timur, H., Şahin, A., Danışman, N., \& Uygur, D. Do vitamin $\mathrm{D}$ and high-sensitivity-C reactive protein levels differ in patients with hyperemesis gravidarum? A preliminary study. Turkish journal of obstetrics and gynecology, 2016; 13(3), 123.

19. Tuan, V. M., Xuan, L. T., \& Nhat, P. Q. Vitamin D Deficiency Rate in First-Trimester Pregnant Women at Ho Chi Minh City. Gynecol Reprod Health, 2019; 3(1), 1-5.

20. Marwaha, R. K., Tandon, N., Chopra, S., Agarwal, N., Garg, M. K., Sharma, B., ... \& Puri, S. Vitamin $\mathrm{D}$ status in pregnant Indian women across trimesters and different seasons and its correlation with neonatal serum 25-hydroxyvitamin D levels. British journal of nutrition, 2011; 106(9), 13831389.

21. Rifas-Shiman, S. L., Rich-Edwards, J. W., Willett, W. C., Kleinman, K. P., Oken, E., \& Gillman, M. W. Changes in dietary intake from the first to the second trimester of pregnancy. Paediatric and perinatal epidemiology, 2006; 20(1), 35-42.

22. Vaziri, F., Nasiri, S., Tavana, Z., Dabbaghmanesh, M. H., Sharif, F., \& Jafari, P. A randomized controlled trial of vitamin D supplementation on perinatal depression: in Iranian pregnant mothers. BMC pregnancy and childbirth, 2016; 16(1), 239.

23. Maltepe, C., \& Koren, G. The management of nausea and vomiting of pregnancy and hyperemesis gravidarum-a 2013 update. Journal of Population Therapeutics and Clinical Pharmacology, 2013; 20(2).

24. Groziak, S., Kirksey, A., \& Hamaker, B. Effect of maternal vitamin B-6 restriction on pyridoxal phosphate concentrations in developing regions of the central nervous system in rats. The Journal of nutrition, 1984; 114(4), 727-732.

25. Unit, G. Treatment of Pregnancy Nausea. Pakistan Journal of Biological Sciences, 2011; 14(16), 817820.

26. Verit, F. F., Erel, O., Sav, M., Celik, N., \& Cadirci, D. Oxidative stress is associated with clinical severity of nausea and vomiting of pregnancy. American journal of perinatology, 2007; 24(09), 545-548.

27. Rayman, M.P. and Stranges, S. Epidemiology of selenium and type 2 diabetes: can we make sense of it? \| Free Radic Biol Med, 2013; 65:1557-1564.

28. Mubder, N. S., Mustafa, S. A., \& Farhan, L. O. Effect of Pregnancy on Selenium, Cupper, Zinc and Others Biochemical Feacture. Baghdad Science Journal, 2013; 10(4), 1182-1189.

29. Tohala, L. M. Serum Magnesium and Copper Levels Amongst Pregnant Women in Mosul City. Rafidain journal of science, 2012; 23(1E), 68-78.

30. Eby, G. A., \& Eby, K. L. Rapid recovery from major depression using magnesium treatment. Medical hypotheses, 2006; 67(2), 362-370.

31. HASHIZUME, N., \& MORI, M. An analysis of hypermagnesemia and hypomagnesemia. Japanese journal of medicine, 1990; 29(4), 368-372.

32. Huang, C.L., \& Kuo, E. Mechanism of hypokalemia in magnesium deficiency. Journal of the American Society of Nephrology, 2007; 18(10), 2649-2652.

33. Acelajado, M. C., Culpepper, R. M., \& Bolton III, W. D. Hyperemesis gravidarum in undiagnosed Gitelman's syndrome. Case reports in medicine, 2016,2016.

34. Aronson, P. S., \& Giebisch, G. Effects of $\mathrm{pH}$ on potassium: new explanations for old observations. Journal of the American Society of Nephrology, 2011; 22(11), 1981-1989. 